\title{
REALIZING LOW COST TOOLING FOR RECONDITIONING OF THREAD ROLL
}

\author{
Manoj Nayak \\ Department of Mechanical Engineering \\ Faculty of Engineering and Technology \\ Manav Rachna International Institute of Research and Studies \\ Faridabad-121010, India
}

\begin{abstract}
The objective of this experimental work is to find the suitability profile of CBN-L tools application in maintenance of thread rolls. Turning experiment were carried out at constant feed and depth of cut but at different low and medium cutting speeds on similar interrupted and continuous work surfaces. The machining experiments showed that the CBN-L tools performed better at $102 \mathrm{~m} / \mathrm{min}$ for interrupt surfaces and require higher cutting speeds for continuous surfaces. At a very low speed of $60 \mathrm{~m} / \mathrm{min}$ the CBN-L tools are prone to chipping of the cutting edge both in continuous and interrupt cutting. It is concluded that a low speed of 100 $120 \mathrm{~m} / \mathrm{min}$ can be effectively used to remove the damaged threads of the thread rolls and a higher speed of 200 $\mathrm{m} / \mathrm{min}$ can be used to generate a fresh surface from the same single inserts. SEM reports showed that while abrasion and adhesion were the dominant wear mechanism, diffusion/dissolutions also occur at low cutting speeds along with tribo-chemical wear.
\end{abstract}

Keywords - Thread rolls, reconditioning, continuous, interruptions

\section{INTRODUCTION}

Dry hard turning is a profitable alternative to finish grinding operation, with the help of developed tool materials like ceramics and CBN. Moreover, the use of cutting fluid is restrained or nearly eliminated in the manufacturing industry thus reducing processing time and production costs (Tonshoff et al 2000). According to cutting conditions, types of cutting are categorized into high speed cutting that provides high efficiency and low speed cutting that realizes low tool cost. In the quest of keeping a low maintenance cost of the dies and thread rolls, the typical problem which arises on the cutting edges of such tools in continuous cutting is development of wear. On the other hand a low speed interrupt cutting results in breakage of tool insert by impact and in high speed interrupt cutting the breakage is caused by the fast growth of crater wear (Omkamuru, 2005). Moreover in heavy interrupt cutting as the stress on the cutting edge increases, tool life becomes more unstable and shorter. As a result, there is little cost advantages of cutting with $\mathrm{CBN}$ tools, and grinding continues to be the primary method of heavy interrupted machining. Besides the undesirable mechanical and thermal shock for a turning insert, the hard interrupt turning operation may generate more specific excitation amplitude into the system that may be undesirable, unless the machine tool, tooling, and part setup are made real rigid and damped. CBN inserts are today tough enough to bear the shock loads. Recently demand for lower machining cost has grown in heavy interrupted cutting and tougher material like $\mathrm{CBN}$ meet the challenges. Since CBN-L tools are cheaper than CBN-H tools, the current study investigates the suitability of using CBN-L tools to turn at low and moderate speeds for both continuous and interrupt machining to realize both technological feasibility and economic viability.

Historically researches in interrupt cutting have lot to offer in terms of the material aspect of the cutting tool more so when the behaviour of the $\mathrm{CBN}$ tool grades varies accordingly to their grain size, $\mathrm{CBN}$ content, binder material and also owing to their different thermal properties. There are two grades of CBN tools i.e. CBN-H and CBN-L (Sandvik Coromat, 1994) with different mechanical and thermal properties (Heath 1986). Literature study shows that CBN-H has longest tool life compared to $\mathrm{CBN}-\mathrm{L}$ during machining of hardened heavy interrupted surfaces because of their high hardness and CBN-L requires medium speed on semiinterrupted surfaces for longest tool life (Chou and Evans 1999). CBN-L tools are more successful in machining continuous and less interrupted work surfaces and are not suitable for heavy interrupted surfaces (Diniz et al 2005) since in CBN-L tools the CBN content is less i.e. the CBN content is replaced by ceramic binder, which results in loss of hardness along with toughness but there is improvement of chemical stability. However, the wear resistance of CBN-L grade is very high, despite lower hardness, which is a puzzling phenomenon (Bossom 1990). Experimental studies conducted on various CBN-L tools in interrupt cutting of hardened steel conclude that the finer grain size of $\mathrm{CBN}$ particles attribute to high wear resistance, high hardness and high transverse rupture strength (Naikal 1991). Experiments have been conducted to study the feasibility of machining hardened work surfaces with no interruption, semi-interrupted and highly interrupted using $\mathrm{CBN}-\mathrm{H}$ and $\mathrm{CBN}-\mathrm{L}$ tools. It was found that the CBN-L tools with low toughness have a tool life similar to $\mathrm{CBN}-\mathrm{H}$ and can withstand the shocks of interruption (Diniz 


\section{International Journal of Engineering Applied Sciences and Technology, 2019 \\ Vol. 3, Issue 11, ISSN No. 2455-2143, Pages 19-24 \\ Published Online March 2019 in IJEAST (http://www.ijeast.com)}

and Oliveria 2008). Evaluation of surface integrity and machinability showed that the CBN-L had better machinability and is superior to $\mathrm{CBN}-\mathrm{H}$ in terms of tool wear and surface integrity (Ko and Kim, 2001). Studies also showed that the tool wear increases with the increase of CBN content in the tool (Eda et al 1980). Some research studies suggested that the longer tool life of CBN-L is due to greater bond strength of the ceramic binder while some others proposed that the welding layers, on the tool flank wear land of CBN-L, create a protection effect (Chou et al 2002). One study reasoned that the lower thermal conductivity of CBN-L leads to the stable protective layer (Hooper et al 1988) and suggested resultant softening of workpiece in the shear zone. Therefore the increase of tool life in case of CBN-L tools at high speeds is due to workpiece softening due to rise in temperature at higher cutting speeds. However when the cutting speed is increased above $240 \mathrm{~m} / \mathrm{min}$, the cutting edges get softer leading to a shorter tool life of CBN-L tools (Oliveria et al 2009). A study on AISI D6 workpiece using CBN tool showed both longest tool life and high volume of material removal at lowest speed using $70 \mathrm{~m} / \mathrm{min}$, high feed value results in high material removal and low feeds resulted in higher tool life and a feed of $0.20 \mathrm{~mm} / \mathrm{rev}$ is recommended for roughing operation (Arsecularanatne et al 2006). Similar was carried out by (Nayak and Sehagal 2015; Nayak et al 2015) on AISI D6 tool steel using CBN-L tools. An experimental investigation done by (Sales et al 2009) on reconditioning of dies of hot forging using carbides, ceramics and $\mathrm{CBN}-\mathrm{H}$. Carbides performance was appreciable at low speeds and low feeds and ceramics did not perform better in all cutting condition. There was drop in performance of CBN$\mathrm{H}$ tools at low speeds but at high cutting speed the performance improved. In the present work, the high cost per cutting edge has been considered for the choice of CBN-L as cutting tool material which is cheaper and superior as compared to $\mathrm{CBN}-\mathrm{H}$. The study focuses on machining hardened damaged layer of hot forging dies (continuous cutting) and damaged threads of the thread rolls (interrupt cutting) at speeds ranging from low to medium. Various mechanisms of tool failure in machining damaged as well as fresh surfaces during continuous and interrupt cutting have also been

The motivation of the research is to provide a cheap solution to machine the used hardened dies and tools. Form tools like thread rolls, knurling tools, dies used for stamping and hot forging, hot extrusion dies, press tools etc. work on extremely aggressive tribological systems. Micro and macro dents on the hot working die surfaces (with depth upto $1 \mathrm{~mm}$ ), damaged threads on thread rolls as shown in Fig. 1. Tools and dies are scraped because of uneconomical machining cost or brought to use by reconditioning. Thread rolls after reaching the end of their useful life require reconditioning either by grinding or by turning in hard condition to produce fresh surface.. Dies and form rolls are converted and brought to use by increasing the internal diameter or turning the outer formed surface. Such turnings are extremely difficult because of the high impact forces generated due to interruption of the cut by the grooves on the die surface or damaged threads on the thread rolls or due to hardened layer on the die surfaces. Thread rolls reconditioning or hot forging die surfaces turning are suitable candidate for both continuous and interrupted turning. This study is done with an aim to explore the suitability of using CBN-L tools as an economical mean for maintenance of hardened dies or form tools. Turning experiment were carried out at constant feed and depth of cut but at different low and medium cutting speeds for both interrupt and continuous machining to affirm an economical method of maintenance of form tools and forging dies

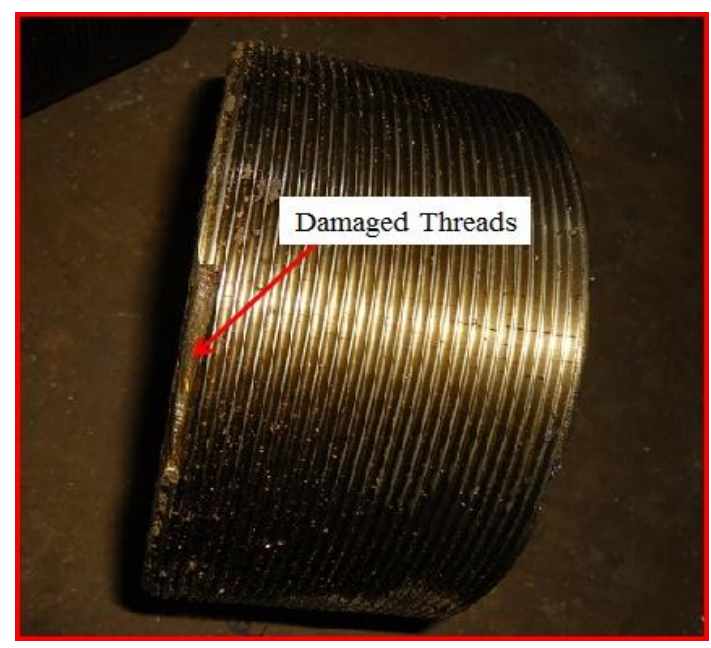

Fig. 1 Damaged threads on thread rolls

\section{EXPERIMENTAL METHOD}

Based on the Sumitomo catalogue, a CBN- L insert of BN300 grade is applicable for both continuous and interrupt cutting of hardened steels and hence was selected for the experimental study. The mechanical and thermal properties of this grade are given in Table Cutting inserts with ISO code 2NU CCGU 09T308 were $80^{\circ}$ rhombus shape tungsten carbides substrates brazed with $\mathrm{CBN}$ tips; cutting geometry was $6^{\circ}$ rake angle, $6^{\circ}$ relief angle, $0.8 \mathrm{~mm}$ nose radius.

Table 1 Thermal and mechanical property of steel

\begin{tabular}{llllllll}
\hline $\begin{array}{l}\text { Tool } \\
\text { Grade }\end{array}$ & Binder & CBN & $\begin{array}{l}\text { Grain } \\
\text { Size }\end{array}$ & Hardness & $\begin{array}{l}\text { Transverse } \\
\text { Rupture } \\
\text { Strength }\end{array}$ & $\begin{array}{l}\text { Fracture } \\
\text { Toughness }\end{array}$ & $\begin{array}{l}\text { Thermal } \\
\text { Conductivity }\end{array}$ \\
\hline CBN-L & TiN & $60 \%$ & $0.5 \mu \mathrm{m}$ & $\begin{array}{l}3300-3500 \\
\text { HV }\end{array}$ & $\begin{array}{l}110-120 \\
\text { Kg/mm }\end{array}$ & $4.0 \mathrm{MPa}(\mathrm{m})^{0.5}$ & $54 \mathrm{~W} / \mathrm{mK}$ \\
\hline
\end{tabular}

Two different work-piece geometries (AISI D6 Tool Steel) were machined before hardening and tempering for two 


\section{International Journal of Engineering Applied Sciences and Technology, 2019 \\ Vol. 3, Issue 11, ISSN No. 2455-2143, Pages 19-24 \\ Published Online March 2019 in IJEAST (http://www.ijeast.com)}

different tests. For continuous machining, the workpiece of $\varnothing$ $42 \mathrm{~mm} \times 160 \mathrm{~mm}$ length cylindrical bars as shown in Figure 2 were used whereas for interrupt machining the workpiece with 6 -slots were prepared by milling slots of $6 \mathrm{~mm}$ width and 8 $\mathrm{mm}$ depth on $\varnothing 42 \mathrm{~mm}$ tool steel bar of length $160 \mathrm{~mm}$ as shown in Figure 3. The experimental work was done on the workpiece bars after turning the outermost oxidized layer by 1 $\mathrm{mm}$ for removal of any scales formed during heat treatment, which could otherwise have an adverse effect on the experimental results.

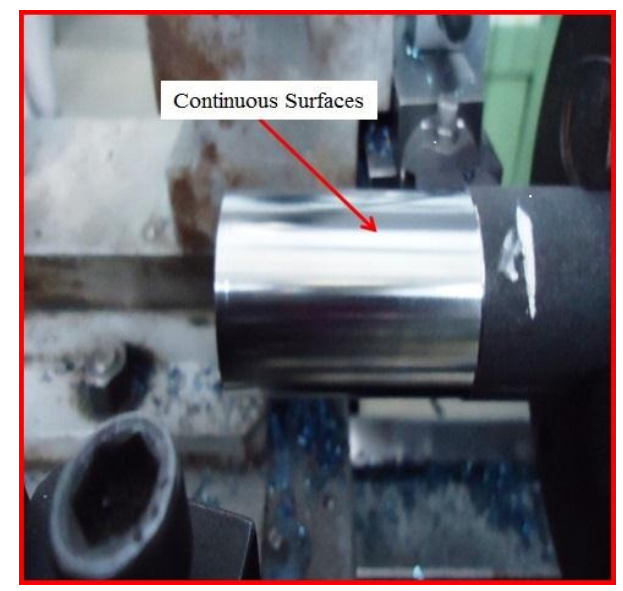

Fig.2 Continuous machining

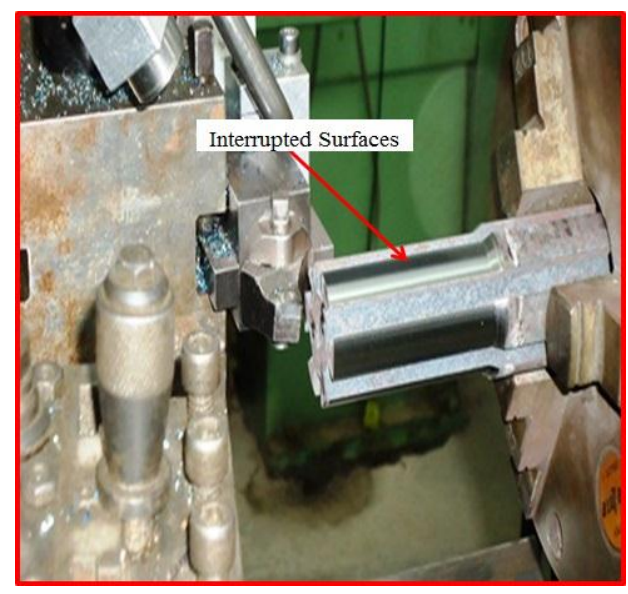

Fig.3 Interrupt machining

The experiments were carried out in an all geared DRO Lathe (Model: Bajaj-Pioneer-175 Geared Headed), 8-spindle cutting speed (8-1200rpm) and 24 no: of feeds. A surface roughness tester (SJ-301 Mitotoyo, Japan), X-axis (drive units) with measuring range of $12.5 \mu \mathrm{m}$ was used to measure the surface roughness $\mathrm{R}_{\mathrm{a}}$ during the experiments. Continuous machining and interrupt machining tests were conducted at two different cutting speeds of 60 and $102 \mathrm{~m} / \mathrm{min}$ at a constant depth of cut of $0.1 \mathrm{~mm}$ and a feed rate of $0.13 \mathrm{~mm} / \mathrm{rev}$. This cutting condition represents machining at low and medium speeds to ensure that the tool wear is not rapid for achieving low tooling cost and sufficient material removal which is critical for reconditioning of dies and rolls. Moreover, depth of cut of 0.1 $\mathrm{mm}$ is a usual value of material stock removal in grinding operation. The feed value was chosen aiming to obtain a surface roughness values close to those obtained in grinding with slightly larger chip thickness and consequently low specific cutting force. This surface roughness criterion is also used because surface finish of $3 \mu \mathrm{m}$ on the roll surfaces or on the die surface is required for their reuse in industry applications. The two types of work surfaces prepared were turned to $75 \mathrm{~mm}$ length in a single pass. One single pass has an interaction cutting time of 3.15 minutes. A maximum of 20 passes were used on each type of workpiece surface at different cutting speeds. Fresh inserts were used for each cutting speed. The machining test was terminated until a fresh insert failed due to chipping/fracture or produced surface roughness greater than $3 \mu \mathrm{m}$. The surface roughness of the work surface was measured at regular interval of $17-20 \mathrm{~mm}$ space along the feed length after each pass to find out the change of surface roughness due to tool wear. Minimum of 9 surface measurements after each pass at $120^{\circ}$ and total of maximum 180 observation of surface roughness were made for each cutting speed.

\section{RESULT AND DISCUSSION}

\section{A. Interrupted Machining}

Interrupt machining tests were done using fresh inserts at two different speeds of 60 and $102 \mathrm{~m} / \mathrm{min}$ at a constant depth of cut of $0.1 \mathrm{~mm}$ and a feed rate of $0.13 \mathrm{~mm} / \mathrm{rev}$. The surface roughness $R_{a}$ values measured were in the range of $0.48-1.15$ $\mu \mathrm{m}$ up to four number of passes for both the speeds. Later on the surface finish obtained at lower speed $(60 \mathrm{~m} / \mathrm{min})$ deteriorated at faster rate as compared to the surface finish obtained while machining at a speed of $102 \mathrm{~m} / \mathrm{min}$. The maximum surface roughness value obtained during machining at $102 \mathrm{~m} / \mathrm{min}$ was $2.0 \mu \mathrm{m}$ upto $20^{\text {th }}$ pass and no chipping of cutting edge was observed as shown in Fig. 5 and the brazed CBN tip was intact. Although crater initiation started after higher number of passes but no complete crater formation was observed as shown in Fig. The cutting edge sustained up to 20 numbers of passes without any chipping giving the desired surface finish.

At a low speed of $60 \mathrm{~m} / \mathrm{min}$ high surface roughness value were obtained immediately after $4^{\text {th }}$ pass. The test was terminated due to extremely poor surface finish. The poor surface finish is due to rapid wear of the tool at low speeds as suggested by (Omkamuru, 2005). and the tools are susceptible to breakage due to impacts. At low speeds the wear of CBN tool is more mechanical than thermally induced (Chou and Evans, 1999). In this experiment the tool failed due to loss of the supporting shim base where the tool tip is brazed as shown 


\section{International Journal of Engineering Applied Sciences and Technology, 2019 \\ Vol. 3, Issue 11, ISSN No. 2455-2143, Pages 19-24 \\ Published Online March 2019 in IJEAST (http://www.ijeast.com)}

in Fig. 4 and the failure is only attributed to the difference in material properties of the shim base and CBN tip as identified by Ghani et al (2008).

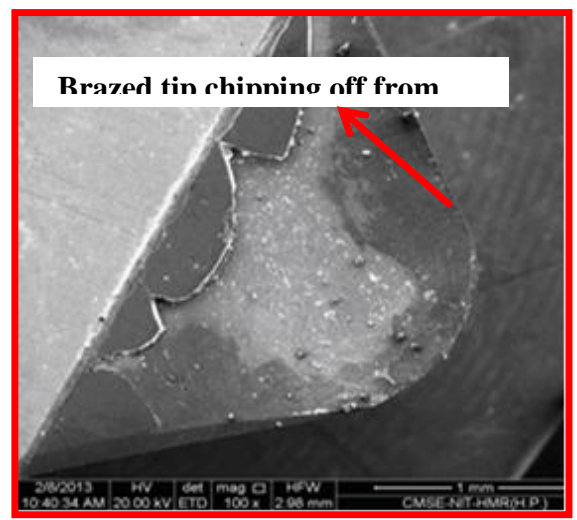

Fig. 4 Interrupt machining at $60 \mathrm{~m} / \mathrm{min}$ and 15 passes

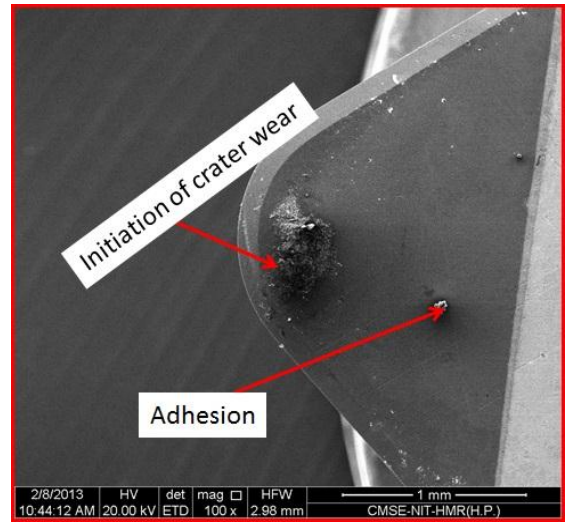

Fig. 5. Interrupt machining at $102 \mathrm{~m} / \mathrm{min}$ and and 20 passes

Reconditioning of thread rolls are done by machining the damaged and blunt threads from the cylindrical surface of the thread rolls. The tools are subjected to impact loads due to the interruption caused by the threads. Since CBN-L tools performs better in medium cutting speed during interrupt turning as per the experimental results, the damaged threads can be removed using CBN-L tools at around $100 \mathrm{~m} / \mathrm{min}$. The medium cutting speeds during turning of damaged threads increase the tool life, thereby giving a cost advantage of CBN tools over grinding the threads.

\section{B. Continuous machining}

The observation was made on the performance of the CBN-L tool at cutting speed of 60 and $102 \mathrm{~m} / \mathrm{min}$, keeping the depth of cut $0.1 \mathrm{~mm}$ and feed rate of $0.133 \mathrm{~mm} / \mathrm{rev}$ constant. Initialization of the crater wear on the rake surface begins immediately and the crater develops as shown in Fig. 7 and extended until it reaches the preceding flank wear. At low speed range this phenomenon weakens the tool nozzle and collapse of the nose is inevitable suggesting these tools are not a good performer for continuous machining below $100 \mathrm{~m} / \mathrm{min}$. The nose cutting edges degraded on each subsequent passes more so after four passes. The surface roughness $\left(R_{a}\right)$ measured on the machined surfaces were in the range of value of $0.53-2.67 \mu \mathrm{m}$ initially with fresh inserts at both the speeds. After four passes the surface roughness value exceeded $3.0 \mu \mathrm{m}$ suggesting the poor performance of CBN-L and its susceptibility to high wear promoted by chipping at a low cutting speed. CBN-L performs better at a speed range of 150$180 \mathrm{~m} / \mathrm{min}$ as suggested by Chou and Evans (2009).

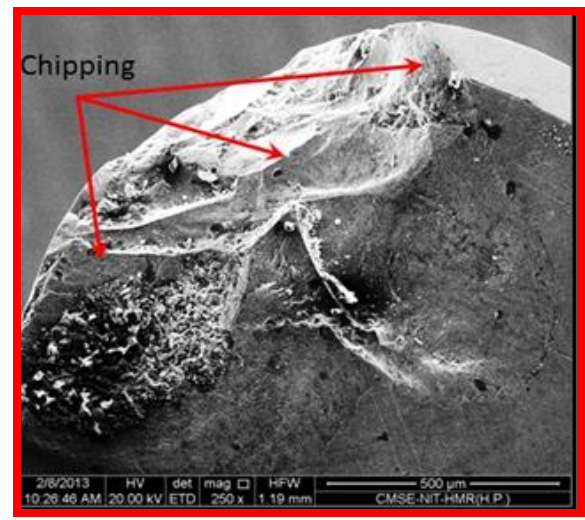

Fig. 6 Continuous machining at $60 \mathrm{~m} / \mathrm{min}$ at 20 passes

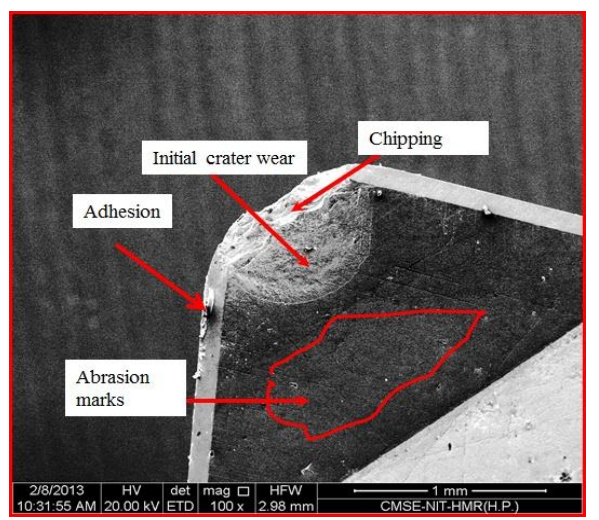

Fig. 7 Continuous machining at $102 \mathrm{~m} / \mathrm{min}$ at 20 passes

During initial passes the tool experienced chipping on the cutting edge, crater wear on the rake face as shown in Figs. 6 and 7, the chipping and the crater increases after each subsequent passes i.e with increased interaction time between tool and work material. The tool experienced a larger crater 


\section{International Journal of Engineering Applied Sciences and Technology, 2019 \\ Vol. 3, Issue 11, ISSN No. 2455-2143, Pages 19-24 \\ Published Online March 2019 in IJEAST (http://www.ijeast.com)}

wear after higher cutting passes, broke of completely from the edge due to highly localized plastic deformation.

During thread roll reconditioning, once the damaged threads are machined, continuous machining is done to generate a fresh surface for re-threading of the rolls. Since CBN-L requires a high cutting speed for better performance in terms of wear as reported by Chou and Evans (2009) and cannot be used at low and medium speeds, at medium speed range of $100-150 \mathrm{~m} / \mathrm{min}$ the tools are susceptible to rapid wear because of continuous engagement of the tool with the workpiece. At higher speeds the increase in temperature softens the workpiece and machining become easier and limits the rapid tool wear. To prevent the CBN-L tools from chipping during continuous machining the speed should be kept in between $150-180 \mathrm{~m} / \mathrm{min}$ to realize the low tool cost. The same CBN$\mathrm{L}$ tool after removing the damaged threads (interrupted surface) can be used for generating the fresh surface using the prescribed cutting conditions.

\section{SEM Analysis of worn out tools}

Although various tool wear mechanisms coexist and dominate in CBN turning of hardened steels, it has been suggested that abrasion, adhesion (possibly complicated by tribo-chemical interactions) and diffusion may primarily govern the $\mathrm{CBN}$ tool wear in hard turning as reported by Huang et al, (2007). The dominant wear mechanism during continuous turning with CBN-L tools is fine scale attrition by micro-fracture and fatigue due to the influence of carbide particles of the workpiece (Chou and Evans, 2009) and abrasive flank wear in interrupt machining (Oliveria et al 2009).

In this study Scanning Electron Microscope (SEM) analysis were used to determine the wear mechanism on the cutting tool. Abrasion and adhesion wear mechanism was observed during continuous machining at cutting speeds of $60 \mathrm{~m} / \mathrm{min}$ and $102 \mathrm{~m} / \mathrm{min}$ as shown in Figs. 6 and 7 due to the abrasive effect of hard carbides particles of AISI D6 steel. Abrasion is caused by hard particles in the workpiece and also by plucked out CBN grains from the cutting tool. Where the binder material has been abraded by the workpiece, the CBN grains are more easily removed and then contribute to further abrasion (Lua et al 1999). During continuous machining at $102 \mathrm{~m} / \mathrm{min}$ it was observed that the edges of the tools were subjected to chipping and fracture and the damage is more severe in case of $60 \mathrm{~m} / \mathrm{min}$ as shown in Fig. 6 .

The continuous impact loads encountered by the tool from the interrupt surface induced high stress and high cutting force resulting in the damage of the CBN tip as shown in Fig.4. Initiations of crater wear on the rake face during interrupt machining as shown in Fig.5 was observed at $102 \mathrm{~m} / \mathrm{min}$. It shows different wear modes at different cutting speeds during interrupted cutting with CBN-L tools; "mechanical wear" for lower speeds and "thermal wear" for higher speeds. The tool life of $\mathrm{CBN}-\mathrm{L}$ tools is very sensitive to cutting speed i.e. it performs better in medium cutting speeds and tool life proportionally reduces at lower speeds due to mechanical impacts rather than thermal shocks as suggested by Chou and evans (1999). High speed interrupt cutting is not possible because at higher speeds the temperature does not reduce due to shorter non-cut period; therefore the hardness of the tool cannot be restored during interrupt cutting.

\section{IV.CONCLUSION}

The major conclusions drawn from this experimental study are:

1. CBN-L can be used for both interrupted and continuous machining effectively and economically.

2. CBN-L tools are suitable candidate for machining hardened damaged layer of hot forging dies, damaged threads of the thread rolls, provided the cutting speed is kept at medium range of $100 \mathrm{~m} / \mathrm{min}$, while removing the interrupt surfaces and at a little higher cutting speed of 180 $\mathrm{m} / \mathrm{min}$ (from previous research) during continuous machining.

3. To generate a fresh surface CBN-L can be successfully used in both continuous and interrupted machining over the prescribed cutting speeds on thread rolls and damaged dies. These tools fail due to chipping on the rake and flank faces at low speeds around $60 \mathrm{~m} / \mathrm{min}$ both in continuous and interrupt machining due to high impact forces on the tool. But these tools perform better in terms of surface finish during interrupt machining at a speed of $102 \mathrm{~m} / \mathrm{min}$.

4. SEM showed abrasion combined with tribo-chemical are the dominant tool wear mechanism, which shows again the decisive effect of the carbide particles of the workpiece on tool wear.

\section{Acknowledgement}

I would like to sincerely thank the Department of Mechanical Engineering, NIT Hamirpur, for conducting the experiments. My sincere thanks to Prof. (Dr). Rakesh Sehgal for his valuable guidance. My sincere thanks to Kunwar Engineering, Faridabad, to supply us a damaged thread roll to work to validate the results of the experiment.

\section{REFERENCE}

[1] Tonshoff H.K., Arendt C. R. R., Amor B. R., (2000) "Cutting Hardened Steel", Annal CIRP, Vol. 49, No. 2, 2000.

[2] Omkamura, K., Kukino, S., Fukaya, T. (2005) "Development of SUMIBORON BN350 and BNC300 for interrupted cutting of hardened steel" SEI Technical Review, No. 59, Jan 2005, pp 66-70.

[3] Heath P. J. (1986) "Properties and uses of Amborite", Industrial Diamond Review, March, pp120-127, 1986.

[4] Chou Y. K. and Evans C. J. (1999) "Cubic boron nitride wears in interrupted hard turning", Wear, 225-229, (1999), 234-245. 


\section{International Journal of Engineering Applied Sciences and Technology, 2019 \\ Vol. 3, Issue 11, ISSN No. 2455-2143, Pages 19-24 \\ Published Online March 2019 in IJEAST (http://www.ijeast.com)}

[5] Diniz A.E, Gomes, D.M, Braghini, (2005) "A turning of hardened steel with interrupted and semi-interrupted cutting", Journal of Material Processing Technology, 159, pp 240-248. [6] Sandwik Coromant, 1994, Modern Metal cutting, $1^{\text {st }}$ edition, AB Sandwik Coromant, Sandwiken, Sweden pp III 45-III 47.

[7] Bossom, P. K. (1990) "Finish machining of hardened ferrous workpiece", Ind. Diam, Rev pp. 228-232.

[8] Naikal, T, Nakantani, S, Tomita, K., Goto, M. (1991) "Hard Turning by PCBN", Conference of Superabrasives, Chicago, II, June 12-14, 1991, pp61-75.

[9] Diniz, A.E., Oliveria, A.J., (2008) "Hard turning of interrupted surfaces using CBN tools", Journal of Material Processing Technology, Vol 195, pp.275-281.

[10] Ko, T.J., Kim, H.S. (2001) "Surface integrity and machinability in intermittent hard turning", The International Journal of Advanced Manufacturing technology", Vol. 18, pp. 168-175.

[11] Eda H, Kishi K, Hashimoto H. (1980) "Wear resistance and cutting ability of a newly developed cutting tools". Cutting tool materials, Proceedings of an International Conference, American Society for Metals, Ft. Mitchell, KY, 15-17 September 1980, pp 265-280

[12] Chou Y.K., Evans C.J., Barash M.M., (2002) "Experimental investigation on CBN turning of hardened AISI 52100 steel". Journal of Material Processing Technology, Vol.124 pp.274-283

[13] Hooper R.M., Shakib J.I., Brookes CA (1988) "Microstructre and Wear of TiC-CBN tools", Material Science Engineering, Vol. 105/106, pp.429-433

[14] Oliveira, A. Diniz, A. E., Ursolino, D. (2009), "Hard turning in continuous and interrupted cut with PCBN and whisker-reinforced cutting tools", Journal of Material Processing Technology 209 pp. 5262-5270.

[15] Arsecularanatne, J. A. Zhang, L. C. Montross, C. and Mathew P. (2006) " On machining of hardened AISI D2 steel with PCBN tools" Journal of Materials Processing Technology Vol. 171, pp.244-252.

[16] Sales, W. F., Costa, L. A., Santos, S. C., Diniz, A. E., Boney, J., and Ezugwa E. O. (2009) “ Performance of Coated, Cemented carbide, mixed-ceramic and PCBN-H tools when turning W320 steel", International Journal of Advance Manufacturing Technology, Vol. 41, pp. 660-669.

[17] Rai G (1993) "The metallurgy of CBN and its wear in high speed machining of ferrous materials", Proceeding of the International Conference on Machining of Advanced Material, Gaithersburg, MD,20-22 July 1993, pp 501-514.

[18] Ghani, M. U., Abukshim, N. A., Sheik M. A. (2008) “An investigation of heat partition and tool wear in hard turning oh H13 tool steel with CBN cutting tools" International Journal Advance Manufacturing Technology, Vol. 39, pp. 874-888.

[19] Chou, Y.K., Evans, C. J.. (1997) "Tool wear mechanism in continuous cutting of hardened tool steels". Wear, 212, pp.59-65.
[20] Luo S.Y, Liao Y.S, Tsai Y.Y. (1999) "Wear characteristics in turning high hardness alloy steel by ceramic and CBN tools" Journal Material Processing Technology, Vol.88, pp114-21

[21] Huang Y., Chou, Y. K. and Liang, S. Y. (2007) "CBN tool wear in hard turning: a survey on research progresses" International Journal Advance Manufacturing Technology. Vol. 35, pp.443-453

[22] Angseryd, J. Coronel, E., Elfwing, M. Olsson, E. Andrén. H. O. (2009) "The micro-structure of the affected zone of a worn PCBN cutting tool characterised with SEM and TEM". Wear, 2009 Vol. pg 1031-1040

[23] Nayak, M., Sehgal, R., 2015. "Effect of cutting conditions and CBN grades on machining of AISI D6 steel during hard turning" Arabian Journal of Science and Engineering, Vol. 40 (4), pp 1151-1164.

[24] Nayak, M., Sehgal, Sharma, R. K. 2015. "Mechanical Characterization and Machinability Behavior of Annealed AISI D6 Cold Working Steel" Indian Journal of Materials Science,ArticleID196178,http://dx.doi.org/10.1155/2015/1961 78, Hindwai Publication Corporation, UK 